\title{
Over sim, cover jamais
}

Over-the-top? Forever. A cover? Never

\author{
José Miguel Wisnik
}

José Miguel Wisnik

Professor sênior de Literatura Brasileira da Universidade de São Paulo (USP), compositor e ensaísta

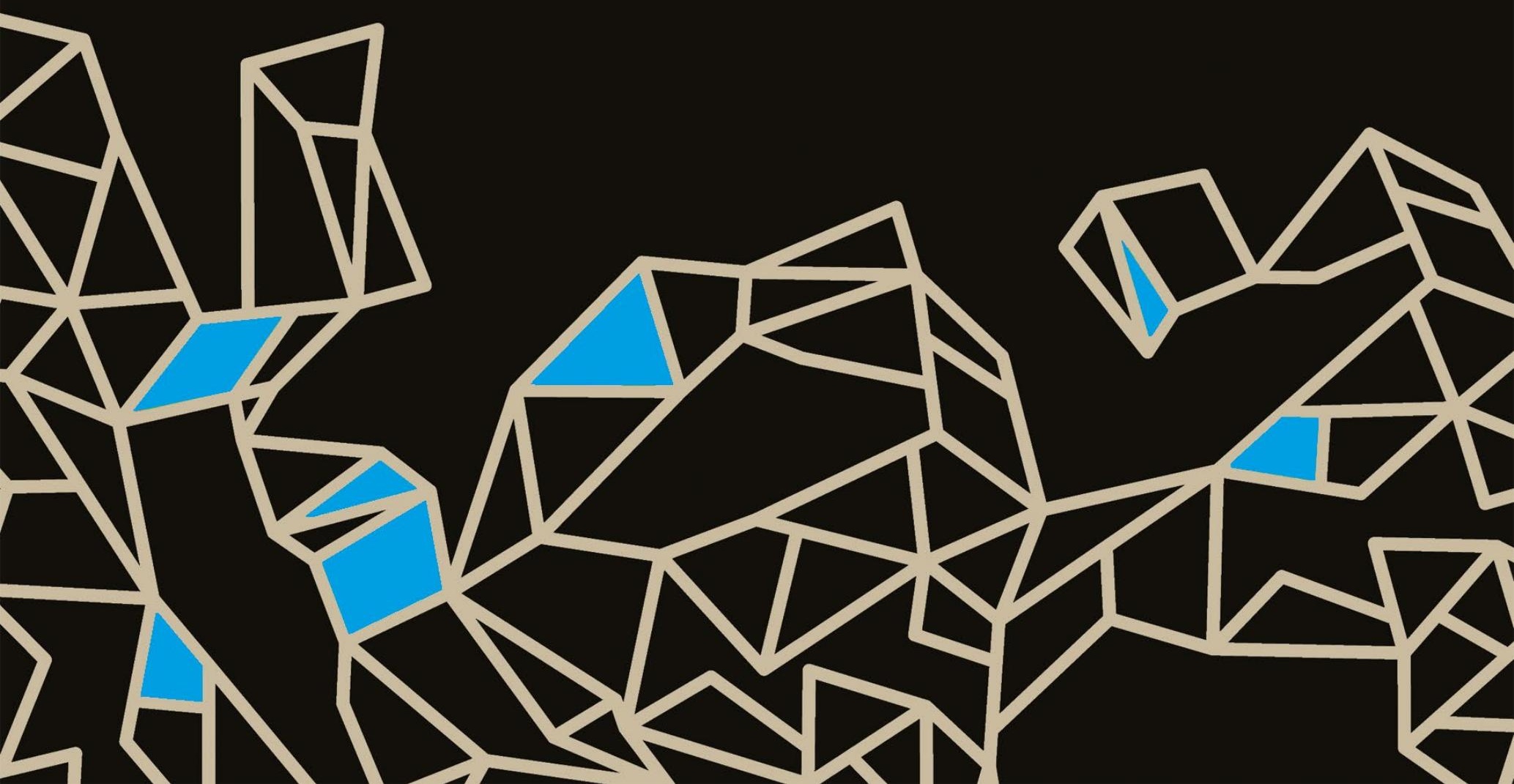


Quando, em 1991, Zé Celso me convidou para atuar em As boas fazendo música ao vivo, era a sua volta aos palcos depois do exílio e do longo ostracismo em que permaneceu ao chegar no Brasil. A peça, com a sua mîse en abîme na qual, como queria Jean Genet, homens encenavam ser mulheres que encenavam ser empregadas domésticas que encenavam ser madame, vestindo em segredo as roupas dela, redobrava-se numa guerra de teatros que contrapunha Raul Cortez no papel de Madame (esplêndida!) e Zé Celso e Marcelo Drummond no papel das criadas - no caso as boas (tradução literal propositalmente "errada" do francês Les bonnes, "servicinho mal feito" de subalternas). Raul, ator colossal, era também uma espécie de alegoria do triunfante teatrão global e, como tal, fora atraído por Zé Celso para uma contracenação litigiosa e fascinante com as empregadinhas do Teatro Oficina. Nessa guerra intestina, a direção era do Zé, mas a estrutura de produção do espetáculo era do Raul. A certa altura da peça, as boas apresentavam em público o borderô da noite à Madame, numa alusão às posições desiguais de domínio e de subalternidade vigentes não só em cena, mas também nas internas da produção.

Engana-se quem pensar que Zé Celso promovia essa batalha teatral com ânimo ácido e destrutivo. Havia, nessa atração pelo embate, a essência de sua paixão pelo teatro como ação e encenação regeneradora da vida pública. Toda a primeira parte da peça transcorria como um excitante Esperando Godot/Madame, a qual surgia gloriosa e roubava a cena da parte central da peça, que não deixava de ser uma fricção luminosa e poderosa entre eles. Fazendo a música, com teclados movidos por disquetes de samplers, acompanhado de dois percussionistas, eu, quase no meio do público, podia acompanhar de perto a curva de excitação de uma plateia vidrada, que atingia o cume e depois se cansava e se desconcentrava na peroração final que Zé Celso primava por encompridar - - motivo de meus eternos pedidos, em vão, de redução e síntese. Uma vez dissemos, eu e Bete Coelho, rindo e participando da plateia de algum dos espetáculos no Oficina, que ele descambava para o over. Ao que rebateu pronto: "Over sim, cover jamais!".

O fato é que, no último dia da temporada no Centro Cultural São Paulo, terminado o espetáculo, a empregada demitiu Madame: Zé Celso comunicou a Raul Cortez que ele não faria parte do elenco que participaria do Festival 
de Teatro de Curitiba. Na cena de bastidores, Raul Cortez passa por mim pisando duro no salto alto, me diz, entrecortado mas elegante, que foi um prazer trabalhar comigo, e ouço seus passos subindo e sumindo pela escadaria da sala Adoniram Barbosa, numa inversão perfeita da aparição sublime em que descia os degraus da escada cênica no meio do espetáculo. Às vezes penso que toda a temporada foi arquitetada inconscientemente por Zé Celso para desembocar nesse ato teatral em que a subalterna assume o poder na contracenação com o teatro hegemônico. Mas para isso seria preciso distinguir Raul Cortez enquanto ator-vodu Madame, que integra com sua ambivalência a força originária do teatro, e Raul Cortez como ator da nova ordem neoliberal que impunha àquela altura, com as prerrogativas do estrelato global, suas condições de produção à partilha do palco. Se o ato final da temporada exacerbou essa dualidade, o ator que Zé Celso demitia não era o primeiro, mas o segundo.

Com o que íamos a Curitiba partindo quase do zero, sem Madame e sem os percussionistas, que também foram dispensados. Desde o começo, Zé Celso queria que eu me caracterizasse como madame entre os dois músicos vestidos de criadas, com o grupo musical espelhando, assim, o palco. Eu reagia dizendo que a redução da música à lógica de classes, que dominava o conflito central, roubava dela a força ritual que atravessa as classes (a peça terminava, de fato, com o encontro ritual, festivo e musical do trio Cosme, Damião e Doum). Sem medo de assumir minhas próprias fantasias, acrescentei que eu era um polaco chopiniano, um príncipe camponês que não ia submeter o seu mito ao teatro burguês de madame. Zé Celso considerou por um momento aquela declaração, dizendo a alguém ao seu lado (à parte, como numa rubrica de teatro): "Ele diz que é um príncipe". E saiu-se com a solução vencedora: os músicos seriam então três marinheiros, remetendo ao Marinheiro da umbanda (entidade cuja imagem foi entronizada ao pé do meu teclado) e também, - ça va sans dire - a Querelle, de Jean Genet.

Feita para a peça, a canção Soneto do olho do cu musicava a tradução de Zé e Marcelo Drummond para o poema de Verlaine e Rimbaud. Uma espécie de Gymnopédie de Satie em feitio de oração ("oculto, com pregas, humilde/ úmido ainda do amor cravo roxo") que decola para um voo à la Lupicínio ("sempre caí de boca e língua nessa ventosa/ minha alma traí na foda material, invejosa") e repousa no mantra final da letra "u". 
Guiado pela sabedoria de Catherine Hirsch, Zé Celso já sabia que a música de Madame seria a da ópera Fidélio, de Beethoven, na qual uma mulher travestida entra na prisão para resgatar seu amante (em correspondência com a peça de Genet, em que Madame está às voltas com a prisão do marido por crime de colarinho branco). Zé Celso me perguntava então qual seria a música das Boas. Eu levei a pergunta para Gilvanete Rocha Silva, que trabalhava e trabalha em minha casa, pedindo a ela que dissesse de que músicas gostava. Gilvanete levou a pergunta mais a sério do que eu imaginava; passou dias fazendo anotações num caderno e me apareceu com trinta e três canções coletadas de memória, com suas letras impecavelmente escritas à mão e, mais que tudo, cantadas por ela com uma voz inconfundível de baiana de Irecê (perto de Irará), marcada ainda por uma afinação íntegra e temperada por aqueles vibratos típicos de duplas sertanejas que ela sabe aplicar com encantadora propriedade. Ela tinha feito uma antologia pessoal de Leandro e Leonardo, Zezé de Camargo e Luciano, Amado Batista e algum Roberto Carlos. No estúdio de Paulo Tatit, Gilvanete gravou doze faixas a capella, irretocáveis, de primeira. Músicos profissionais sempre repetem várias vezes ao gravar e ainda pedem, a certa altura, para fazer "a boa", quando sentem que estão na iminência do melhor take. Gilvanete não tinha esse problema. Sua emissão já era sempre, e imediatamente, a boa.

Raul Cortez disse que sua dicção era notável; mais tarde, em outras circunstâncias, Gilberto Gil me disse que ela era daquelas pessoas que cantam sem o recurso ao ego. Não estou dizendo que Gilvanete fosse uma revelação de cantora a ser lançada no mercado. Muito ao contrário. Radicalmente avesso ao mercado, seu canto singelo e firme bebia nos sucessos do rádio, que viravam então uma espécie de cantochão íntimo na voz solitária de alguém cantando enquanto trabalha. Enquanto o público entrava no teatro e contrarregras vestidas de boas faziam a arrumação de palco que figurava a arrumação dos aposentos de Madame, aquela voz conferia ao ambiente uma serenidade profunda e quase religiosa.

Lista de compras, de Amado Batista, cuja letra é uma relação de itens de supermercado por meio dos quais se conta uma estória de banalização do amor no casamento, era, nas circunstâncias, um achado, além de ser sua pièce de resistence. Em 2002, Gilvanete participou como nossa convidada de 
um episódio dos "Encontros improváveis" no Centro Cultural Banco do Brasil (CCBB), cantando justamente a Lista de compras. Zé Celso previu que ela seria ovacionada em cena aberta - dito e feito. Ao fazer a trilha de Parabelo para o grupo Corpo, junto com seu quase conterrâneo Tom Zé, convidamos Gilvanete para gravar Cego com cego. O espetáculo percorreu mundos e eu mesmo presenciei uma noite, no Théatre des Champs Elysées, em Paris o mesmo onde foi estreada a Sagração da Primavera de Stravinski e La mer de Debussy -, o momento em que se ouviu, na escuridão total, a voz de Gilvanete Rocha Silva entrar cantando: "eu vi o cego lendo a corda da viola/ cego com cego no duelo do sertão".

Enquanto, em Curitiba, os maiores problemas enfrentados pelas demais companhias, que vinham de bem-sucedidas temporadas nacionais, resumiam-se, por exemplo, a um ajuste na barra do vestido de uma atriz, nós tínhamos que levantar em pouquíssimos dias um espetáculo que envolvia contrarregras em cena e músicos, todos arregimentados in loco e nas vésperas. Isso sem falar da pergunta aberta sobre a substituição de Madame. Zé Celso tomara a decisão temerária de ele mesmo substituir Raul Cortez, deixando o lugar de Solange para outro ator que também entrava cru na aventura. Quem esqueceria, no entanto, o pedigree de Raul Cortez, seu sociotipo de rôle, sua Madame longilínea impecavelmente racée, cheia de aprumo e aplomb, o caimento perfeito do vestido longo, o movimento das mãos e o discreto meneio das ancas?

O ensaio geral, que se prolongou pela madrugada e só terminou ao amanhecer do dia da estreia, foi uma tragédia de erros patética. Contrarregras-atores e músicos batiam cabeça, todos tentando bravamente se acertar em meio à multidão de detalhes que não se juntavam. No papel de Madame, Zé Celso se parecia mais com uma espécie de Franco Montoro vestido de túnica romana. Dissemos tudo isso para ele no café da manhã, confiando cegamente no seu taco. Ele nos dizia, com simplicidade, que o dirigíssemos. Na verdade, retirou-se para seu quarto de hotel durante o dia inteiro e só chegou no teatro já à noite, envolvido num casaco de pele e cantando uma canção do repertório de Isaurinha Garcia que chamava para si a luz dos holofotes. Madame renascia vinda da lama das canções da noite. 
Na preleção antes da estreia, Zé Celso falou a toda equipe que a peça de Genet girava inteira em torno de um erro de contrarregragem - a empregada se denuncia ao esquecer um fone fora do gancho. Nossos erros não deveriam, pois, ser tomados como culpa, mas se assumir como a própria matéria que movia o jogo. Naquele momento eu senti que estava exatamente onde queria estar, no lugar em que a vida se assumia na precariedade e se revirava em outras por obra da fé cênica. Depois dos dois espetáculos no Festival, Yacoff Sarkovas, que fazia a produção, nos contou que, entre os convidados estrangeiros ali reunidos, a reação não foi morna: houve os que detestaram com todas as forças, e os que aderiram entusiasticamente àquele Genet tropical fora de esquadro.

Uma vez Antunes Filho me chamou para conversar sobre a música de seu Gilgámesh em preparação. Não posso deixar de pensar nas diferenças que senti entre os dois. Antunes me explicava didaticamente o que era um texto milenar e me chamava para seu maravilhoso parque teatral como se ele fosse o Lobo e eu a Chapeuzinho, com um gesto de mão voltada para baixo num movimento aliciante que dissesse: "Vem, vem conhecer o mundo, vem". Zé Celso é o contrário: para o bem ou para o mal dos resultados, te atira às feras como se dissesse, cheio de tesão: "Vá ser gênio!" É o que acontece no seu Ham-let, que aproveitava no título a sacada de Gerald Thomas, sacada por sua vez de Beckett, de que no nome do príncipe está cifrado um recado sobre o próprio teatro - Ham-let: solta o canastrão.

Num lance novamente temerário, Marcelo Drummond, investido de um desafio tremendo, tinha que saltar diretamente da periferia de Madame, como a Clara de As boas, para o personagem que está no epicentro do teatro mundial de todos os tempos. Mas isso se fazia por uma subversão de base do pressuposto que associa Hamlet ao figurão do grande ator. Pregando uma peça nessa peça dentro da peça que é Hamlet, o príncipe da melancolia se assume como canastrão e renasce, nisso, como um inesperado HamletCazuza, rebelde sem causa. Tempos depois, vendo na televisão um Hamlet feito por Mel Gibson, me convenci definitivamente da pertinência e da genialidade do Hamlet de Marcelo Drummond.

A princípio eu não ia fazer a temporada, mas acabei socorrendo a música do espetáculo quando este se viu abandonado pela banda, junto com 
Chico Pinheiro, Cacá Machado, Sérgio Espíndola, reunidos do dia para noite num único ensaio para enfrentar as sete horas de função. A peça tinha maravilhosas canções de Péricles Cavalcanti, e eu contribuí com Massacração da primavera (referência ao massacre do Carandiru) e com a Primavera propriamente dita, que abria e fechava o espetáculo, marcando o renascimento do Oficina naquela primavera de 1993.

A montagem contava com atuações maravilhosas de Pascoal da Conceição, Alleyona Cavalli, Alexandre Borges e Julia Lemmertz. Gerald Thomas e Caetano Veloso escreveram coisas entusiásticas sobre o "Hamlet do Oficina" na Folha de S.Paulo, e o espetáculo viveu dias grandiosos de público. Inesperadamente ou não, atraiu uma plateia juvenil que se identificava apaixonadamente com aquele filho problemático e todo o alucinante contexto teatral em que ele se inseria. O Ham-let era também Hamleteen.

Depoimento bem pessoal, mas não só: para meu filho e filhas, a vida se divide entre antes e depois de Ham-let. Eles estão entre aqueles que viram mais de vinte vezes, conhecem tudo de cor e salteado e têm o espetáculo na memória como uma espécie de partitura da vida. Guilherme atuou mais tarde como operador de peen-been, e seguiu dando apoio às lutas do Oficina enquanto arquiteto, urbanista e ensaísta. Marina e lara, que já tinham visto As boas quando meninas, que se apaixonaram por teatro e depois se formaram como atrizes no Indac, exigiram, com ou sem a minha autorização, atuar no coro de As bacantes quando tinham em torno de quatorze e quinze anos. Eu me saio pelo humor, dizendo que, como não havia mais bons colégios de freira como antigamente, o Oficina foi a coisa mais próxima que encontrei. Tudo indica que a experiência foi maravilhosa para a formação delas. Recentemente, já compositora com dois discos lançados, Marina reafirmou aquele mergulho adolescente voltando a fazer Bacantes, vinte anos depois.

Marina e lara conheceram Daniela - minha amada filha fora do casamento, a quem dediquei a canção $D N A$ - no dia em que as levei juntas, pela primeira vez, ao Ham-let. Com o tempo, elas se tornaram inseparáveis como as três irmãs, mais uma referência à peça de Tchekhov e ao repertório do Oficina.

Numa sequência quase orquestrada, Laura Vinci, minha mulher (acho pouco chamá-la de "minha companheira") engajou-se como diretora de arte na produção de Cacilda! e de A terra. Artista plástica, fez no Oficina 
a passagem que a define hoje como artista visual ao mesmo tempo que como mulher de teatro.

No domingo de carnaval de 1994, fizemos Mistérios gozosos, poema dramático de Oswald de Andrade, em praça pública no centro de São Paulo. Sobre os poemas de Oswald compus Noturno do Mangue, Flores horizontais e Coração do mar, essas duas últimas gravadas por Elza Soares, a diva dionisíaca da tragycomediaorgia que Zé Celso preconiza. A estação do ano já era outra, e impôs-se compor Verão. No outono, com um Ham-let desagregado e de volta ao Oficina, foi a vez de Outono ("os soluços longos dos violões do outono/ ferem meu coração com um langor monótono" - tradução propositalmente livre dos versos de Verlaine, com violões no lugar dos violinos). Inverno foi feita mais tarde para a temporada de Mistérios gozosos no Oficina, completando um ciclo de quatro canções, todas elas referidas de algum modo à vida da companhia em cada momento, e, no caso desta, descortinando o

\section{Anhangabaú da feliz cidade.}

Um dos momentos sublimes que eu vivi em toda a minha experiência com o Oficina foi no ensaio geral de Mistérios gozosos em praça pública, ensaio que atravessou a noite e terminou, para variar, quando o dia nascia. Só naquela hora conseguíamos passar pela primeira vez o espetáculo inteiro. Populares já circulavam pela cidade, e o movimento do dia, mesmo sendo um domingo de carnaval, começava em ritmo e luminosidade de ainda madrugada. Curiosos paravam diante da pista erguida em palco, na qual se movimentavam atores e atrizes cercados de refletores e música.

O texto de Oswald é forte e ataca com crueza expressionista os temas da prostituição e da pobreza, nada estranhos à região onde estávamos. Mas era estranha aquela exposição obscena - no sentido também de fora da cena teatral e do público que lhe corresponde -, exposição nua e crua dos temas, dos corpos, das palavras. Não se tratava, vejam bem, do festival de nudismo que depois se naturalizou no espaço do Teatro Oficina com seu público cativo. Eram as mulheres, a Mulher, a Prostituta Sagrada, com suas bocetas arregaçadas em plena praça pública. Era mais do que uma afronta ao machismo e às defesas psicológicas do moralismo comum, dos quais se poderiam esperar todos os ataques de volta, e eles estiveram na iminência de acontecer. Mas havia uma solenidade muda no ato da nudez, e um desnudamento tão 
concreto, em cena, de tudo envolve a luta da vida por viver, que baixou ali um silêncio de outra natureza, naqueles homens operários parados - um choque e, ao mesmo tempo, um reconhecimento dentro do mais total estranhamento, uma transformação, um acontecimento (já que só o impossível acontece).

Por ser músico - cantor, pianista e compositor - Zé Celso, quando descreve a música que deseja para um espetáculo, faz parecer que ela já está pronta no ar e virtualmente ali. Foi assim que fizemos São Paulo Rio, um extra para os Mistérios gozosos; Cacilda, valsa dedicada a minha amada Bete Coelho ("com que lábios te beijei/ lábios de amor/ lábios de atriz"); Comida e bebida, parceria para Bacantes, com texto de Eurípedes convertido em música brasileira (eu fiz a melodia da parte inicial declamatória, e Zé Celso sacou que ela podia ser cantada como um samba rápido ou um chorinho de Ademilde Fonseca); Homem forte, sobre versos de Sousândrade, e Hégira para Os sertões.

Volto aos "Encontros improváveis", que fizemos no CCBB em 2004, acompanhados do maravilhoso músico mineiro Kristoff Silva. Considero esse show, facilmente encontrável no YouTube na íntegra, o sumo de tudo que tentei contar aqui. Não um encontro improvável, mas um encontro órfico-dionisíaco mais do que provado, como prova ao final o nosso dueto em Sem fantasia, de Chico Buarque. Zé Celso diz que é a melhor versão já gravada dessa canção, e eu concordo. É, no mínimo, a versão mais fantasiosa e mais sem fantasia de Sem fantasia. Só vendo.

Autor convidado 
